\title{
O discurso jornalístico a respeito do progresso no Rivale no tempo da construção da barragem de Sobradinho ${ }^{1}$
}

\author{
Andréa Cristiana SANTOS ${ }^{2}$ \\ Edonilce Rocha BARROS ${ }^{3}$ \\ Rafhael NOBRE
}

\begin{abstract}
Resumo:
Este artigo analisa a retórica discursiva do Rivale - Renovação e Integração do Vale -, que circulou em Juazeiro (BA), promovendo o debate público a respeito da construção da barragem de Sobradinho (BA). O estudo realizou pesquisa documental em 139 edições, referentes aos anos de 1973 a 1979, tendo como umas das técnicas a análise do discurso. Investiga-se as práticas jornalísticas e os textos de Walter de Castro Dourado, Ermi Ferrari Magalhães e Dom José Rodrigues, que fizeram questionamentos a respeito dos impactos sociais e econômicos circunscritos ao projeto. O jornal funcionou como aparelho ideológico do Estado, utilizando-se de uma retórica discursiva que representava os interesses do Estado e elites locais, embora alguns cronistas tenham tido posicionamentos divergentes a respeito da edificação da represa.
\end{abstract}

Palavras-chave: história do Jornalismo; progresso; desenvolvimento; barragem.

\section{The journalistic discourse about progress in the Rivale at the time of the construction of the Sobradinho dam}

\begin{abstract}
:
This article analyzes the discourse rhetoric of the newspaper Rivale - Renovação e Integração of the Vale -, which circulated in Juazeiro (BA), promoting public debate about the construction of the Sobradinho dam, in Bahia. The study carried out documentary research in 139 editions, from 1973 to 1979 , using discourse analysis as one of its techniques. Journalistic practices are investigated and texts published by Walter de Castro Dourado, Ermi Ferrari Magalhães and Dom José Rodrigues who questioned the social and economic impacts project and its consequences for the riverside population. O newspaper was a vehicle that worked as an ideological State tool, using a discursive rhetoric that represented the interests of the State and local elites, although some chroniclers had made divergent positions regarding the construction of the dam.
\end{abstract}

Keywords: history of Journalism; progress; development; dam.

\footnotetext{
${ }^{1}$ Este artigo teve uma versão preliminar publicada nos Anais Eletrônicos do XXI Congresso de Ciências da Comunicação na Região Nordeste, em São Luís, Maranhão, em maio de 2019. O atual texto foi alterado com novo recorte analítico: ampliação do corpus de análise com maior número de edições e investigação do discurso dos colunistas Ermi Ferrari e Dom José Rodrigues, o que confere originalidade ao tema.
}

2 Doutora em Comunicação, professora do curso de Jornalismo em Multimeios, da Universidade do Estado da Bahia, campus Juazeiro. E-mail: andcsantos@uneb.br.

${ }^{3}$ Doutora em Ciências Humanas, professora do Programa de Pós-Graduação em Educação, Cultura e Territórios Semiáridos (PPGESA).E-mail: ebarros@uneb.br.

${ }^{4}$ Bacharel em Jornalismo em Multimeios pela Universidade do Estado da Bahia, bolsista de Iniciação Científica da Fundação de Amparo à Pesquisa do Estado da Bahia (FAPESB), 2018/2019. E-mail: rafhaelnobre4@gmail.com. 


\title{
El discurso periodístico sobre el progresso en Rivale en el tempo (ou durante) la construcción de la presa de Sobradinho
}

\begin{abstract}
Resumen:
Este artículo analiza la retórica discursiva del Rivale - Renovación e Integración del Valle -, que circuló en Juazeiro (BA), promoviendo el debate público sobre la construcción de la presa de Sobradinho (BA). El estudio realizó una investigación documental en 139 ediciones, referentes a los años de 1973 a 1979, teniendo como una de las técnicas el análisis del discurso. Se investigan las prácticas periodísticas y los textos de Walter de Castro Dourado, Ermi Ferrari y Dom José Rodrigues, que hicieron cuestionamientos sobre los impactos sociales y económicos circunscritos al proyecto. El periódico funcionó como un aparato ideológico del Estado, utilizando una retórica discursiva que representaba los intereses del Estado y de las élites locales, aunque algunos cronistas tuvieron posiciones divergentes con respeto a la edificación de la presa.
\end{abstract}

Palabras clave: historia del periodismo; progresso; desarrollo; presa.

\section{Introdução}

Em 1977, a dupla Sá e Guarabyra lançou a música Sobradinho, que narrava o drama da população expulsa das cidades de Remanso, Casa Nova, Sento-Sé e Pilão Arcado, situadas no norte da Bahia, para dar lugar à formação do lago de Sobradinho. Os cantores retrataram a tristeza da população que se deslocaram de seus espaços de convivência, referência e sociabilidade: “Adeus Remanso, Casa Nova, Sento-Sé. Adeus Pilão Arcado. Vem o rio te engolir. Debaixo d'água, lá se vai a vida inteira, por cima da cachoeira, o gaiola vai subir. Vai ter barragem no salto do Sobradinho e o povo vai-se embora, com medo de se afogar" (SOBRADINHO, 2019).

$\mathrm{Na}$ época, foram deslocadas 70 mil pessoas que sofreram a pressão do Estado, representado pela Companhia Hidrelétrica do São Francisco (CHESF), as quais tiveram de deixar suas moradias e propriedades rurais para dar lugar à formação do lago artificial de 4.214 $\mathrm{Km}^{2}, 350$ km de extensão e 10 a 40 km de largura, com capacidade de armazenar até 34 bilhões de metros cúbicos de água (COSTA, 1990). As antigas cidades ${ }^{5}$ ficaram submersas no lago, e as comunidades foram transferidas para a nova sede dos municípios e para outras regiões.

Criada inicialmente para regularizar o fluxo de água necessário para gerar energia na Usina de Paulo Afonso, a barragem de Sobradinho dista de Salvador cerca de 550,0 km e, da cidade de Juazeiro, $50 \mathrm{~km}$. Ela fez parte da política desenvolvimentista assumida pelo governo

\footnotetext{
${ }^{5}$ A única cidade que não foi inundada foi Pilão Arcado, mas, mesmo assim, a população se deslocou para o novo município.
} 
militar na década de 1970, cuja retórica discursiva afirmava que o empreendimento levaria o progresso às regiões menos desenvolvidas do país (ESTRELA, 2004). Nesse mesmo período, outros projetos hidrelétricos foram incentivados, nos quais se inserem, além de Sobradinho, a construção das usinas de Itaipu (central hidrelétrica na fronteira entre o Brasil e o Paraguai) e Itaparica (BA).

O Governo Federal, por meio do Ministério de Minas e Energia, avaliava que a região apresentava desenvolvimento econômico inexpressivo devido aos períodos prolongados de estiagem e pela existência de terras áridas. Assim, além da perspectiva da obra de promover o progresso econômico, as ações do Estado almejavam conectar o país à economia internacional, à custa de empréstimos, reforçando o discurso nacionalista e mantendo o controle político em negociação com as elites locais (ESTRELA, 2004).

Foi nesse contexto que surgiu, em 1972, o Rivale, empreendimento societário do economista Flávio Luiz Ribeiro Silva, do agrônomo Jorge Khouri Hedaye e do médico Paganini Nobre Mota. ${ }^{6} \mathrm{O}$ periódico se consolidou entre os profissionais liberais e setores da burguesia7 local, sendo considerado representante da "nova etapa da imprensa interiorana" (RABELO, 2014). Outros profissionais formaram o quadro de fundadores do veículo de comunicação, como Ermi Ferrari Magalhães, ex-barqueiro e escritor, e Walter de Castro Dourado, comerciante e autodeclarado historiador, que publicaram artigos de opinião em colunas específicas.

Devido ao impacto da construção da barragem de Sobradinho para a região, investigamos, neste artigo, como o Rivale se utilizava da dimensão textual e de práticas jornalísticas para se posicionar favorável ao empreendimento, a partir da categoria analítica do progresso, tema recorrente no periódico. A pesquisa se inseriu no campo da história da imprensa, abordando a trajetória do jornal no contexto de uma micro-história da comunicação para analisar os processos micro e macrossociais relacionados às práticas jornalísticas (SANTOS, 2016).

\footnotetext{
${ }^{6}$ Paganini Nobre Mota participou no primeiro ano da criação do jornal. Depois, desfez-se da sociedade e fundou o Jornal de Juazeiro, que até hoje circula como Diário da Região.

$7 \mathrm{O}$ termo "burguesia" se refere à elite local formada por grandes comerciantes e profissionais liberais, como conceituou Chilcote (1990). Esses profissionais retornavam à cidade, após terem concluído cursos universitários em Salvador (BA).
} 
O projeto da micro-história permite construir uma análise atenta ao contexto e processos sociais, inclusive trajetórias individuais percebidas nas suas relações com os outros, e identidades, as quais se operam por meio de uma rede de concorrência, solidariedade, aliança. Nessa concepção, não existe simplesmente a leitura do contexto global para situar e interpretar os textos. Conforme Revel (1998), são adotados procedimentos para que o pesquisador possa reconstituir a multiplicidade dos contextos, necessária à compreensão do fenômeno.

Recorremos também à noção de rastro no contexto do circuito de comunicação. Nesse sentido, os produtos comunicativos estabelecem uma intrínseca relação do texto com o seu referente, como afirma Barbosa (2010). Essa relação produz rastro que permite que as mensagens do passado possam chegar até o presente e que sejam interpretados pelo pesquisador na sua dimensão narrativa como ações de comunicação. Compreendemos ainda o jornal como um fragmento, um artefato que nos chega ao presente pelo conjunto de materiais produzidos em um passado e em determinadas condições (LOWENTHAL, 1998).

A pesquisa seguiu a abordagem qualitativa, com a produção de inventários do jornal para identificar os textos jornalísticos e opinativos a respeito do acontecimento. Após, utilizouse a análise do discurso para entender as formações discursivas e ideológicas. O recorte analítico considerou as seguintes dimensões: o quadro da empresa jornalística, fonte de enunciação discursiva; os aspectos históricos e sociais que fundamentam a trama do discurso; e a dimensão do interdiscurso (BRANDÃO, 1994).

Assim, as formações discursivas são compreendidas como o espaço no qual os enunciados são formados e reformulados para reforçar uma ideia. Entendemos ainda que a instituição jornalística compartilha códigos linguísticos, ideologias e favorece a mediação social. A instituição jornalística é fonte enunciadora do "poder simbólico", definido por Bourdieu (2003, p. 15), que o classifica como invisível, irreconhecível, transfigurado e legitimado, capaz de produzir efeitos reais na vida das pessoas, e que é exercido por aqueles que dominam os sistemas simbólicos (a arte, a cultura, a religião, a língua, o discurso), colaborando para estabelecer uma ordem, um sentido sobre o mundo. É pertinente pensar o Rivale como um instrumento simbólico de dominação, à medida que contribuiu para dar legitimidade social à narrativa sobre a construção da barragem de Sobradinho. 
A coleta de dados foi realizada em 139 edições, publicadas no período de 1973 a $1979^{8}$. Desse material, verificamos o discurso da empresa jornalística a respeito do tema progresso e o debate promovido pelos cronistas Walter de Castro Dourado, Ermi Ferrari Magalhães e o articulista Dom José Rodrigues de Sousa. A partir desse recorte analítico, a problemática de pesquisa que nos guiou foi investigar de que forma o discurso jornalístico no Rivale pode ter provocado o silenciamento das questões socioeconômicas e ambientais envolvidas na construção da barragem de Sobradinho. A intenção foi analisar a contribuição dos colunistas e articulistas para a promoção do debate público relacionado às questões circunscritas à edificação da represa e identificar as contradições presentes na narrativa jornalística.

\section{Rivale e o projeto de modernização}

O periódico se posicionou, desde o primeiro editorial, como o porta-voz da população para defender o progresso da região, conceito associado ao desenvolvimento dos municípios de médio porte que iniciavam processo de modernização. Divulgando variados temas, o Rivale surgiu em um período de transformações tecnológicas que mudaram o modus operandi das redações. Tais transformações são decorrentes de um processo de modernização e profissionalização da empresa jornalística iniciado na década de 1950, cujas mudanças perpassaram o campo social, político e cultural (RIBEIRO, 2010). Assim, o jornalismo brasileiro assumiu um caráter empresarial, depois da ascensão do capitalismo e do modelo de desenvolvimento nacional adotado pelo governo brasileiro.

A linha editorial do Rivale fazia referência às políticas públicas desenvolvimentistas para as cidades de médio porte, como se observou na $10^{\text {a }}$ edição do jornal, de 15 de julho de 1972, em comemoração aos 94 anos de emancipação política de Juazeiro, cuja população, à época, era de 61 mil habitantes.9 Para a empresa jornalística, em consequência do contexto de

\footnotetext{
${ }^{8}$ O material coletado se encontra digitalizado no Acervo Maria Franca Pires, localizado no Departamento de Ciências Humanas (DCH), da Universidade do Estado da Bahia, campus III. O acesso se dá mediante solicitação de consulta por email ascomfrancapires@gmail.com.

9 Juazeiro tinha 61.648 habitantes, segundo Censo 1970 (ANUÁRIO..., 1973, p. 99). No Censo 2010, a cidade registrou 197.265 pessoas (ANUÁRIO..., 2021, p. 475).
} 
políticas públicas para incentivar a implantação dos perímetros de irrigação na região, era necessário "um órgão capaz de levantar a bandeira do nosso progresso, porta-voz dos anseios da população da região, levando a todos os recantos da Pátria a mensagem de um povo empenhado na construção do futuro" (PARABÉNS...,1972, p. 1).

O periódico demonstrou posicionamento vinculado aos interesses das elites políticas desde o princípio. Contudo, a enunciação discursiva incorporou os processos de profissionalização do campo jornalístico, assumindo um lugar de neutralidade e "gênero de estabelecimento de verdades" (RIBEIRO, 2010). Foram adotadas restrições formais, como o estilo sintético no formato das notícias e na incorporação do lead, aumentando a comunicabilidade das mensagens, bem como a distinção de espaços para o texto opinativo com as colunas e artigos assinados. Porém, os textos não podem ser interpretados sem pensar a relação contextual dos sujeitos políticos e o público leitor.

Identificamos a influência das normas de objetividade e imparcialidade na publicação de cadernos especiais, mas também os interesses ideológicos e as contradições a respeito da construção da barragem de Sobradinho. No caderno especial "Sobradinho em Debate", de 15 de abril de 1973, o jornal recorreu à narrativa do progresso para dar ênfase à obra, naturalizando e invisibilizando a situação dos ribeirinhos. O Rivale reconheceu que os municípios seriam inundados com a construção do lago, "mas a coisa não é tão drástica como se anuncia. As providências cabíveis e humanas estão sendo tomadas para que ninguém fique desabrigado ou prejudicado (BARRAGEM..., 1973, p. 1).

Este movimento de supressão e invisibilidade dos problemas sociais a serem enfrentados pelas populações ribeirinhas foi assimilado pelas elites locais e ganhou visibilidade no periódico. No caderno especial "Sobradinho em Debate", o deputado da Aliança Renovadora Nacional (Arena), Jayro Sento-Sé, leu na Assembleia Legislativa da Bahia o relatório do engenheiro responsável pela construção da barragem, Eunápio Peltier de Queiroz, enviado ao presidente das Centrais Elétricas Brasileiras S/A, Mário Penna Bhering (SENTO SÉ, 1973, p5). A leitura do documento foi uma demonstração do alinhamento e confiança pelo trabalho executado por Eunápio Peltier de Queiroz. Contudo, no texto confidencial, é feito um diagnóstico social, com discurso de estereotipia, a respeito da população, como pode ser observado no destaque abaixo: 
[...] Analfabeto, sem usufruir qualquer benefício de comunicações de massas, seus contatos humanos restritos ao seu próprio nível, com os vizinhos e nas feiras - sua mentalidade não pode evoluir, considerando-se primitivo, sem poder aquisitivo, sem aspirações, conformado e dominado pelo pavor ao desconhecido. Assim, agarram-se ao rio que lhe assegura a sobrevivência e às crenças que o confortam. - Além de tudo, com justa razão, profundamente sentimental para como seu rio, por afeição - O VELHO CHICO. Socialmente é, pois um ser desvinculado, cultural e economicamente, do resto país. (QUEIROZ apud SENTO-SÉ, 1973, p. 5).

$\mathrm{Na}$ lógica, o discurso do engenheiro Eunápio Peltier de Queiroz, reproduzido por Jayro Sento-Sé (1973) de desqualificação do modo de vida tradicional do ribeirinho procura dar legitimidade à expansão do capitalismo e ao desenvolvimento pensado pelo Estado para todo o país, com apoio de elites locais. Na concepção de Dupas (2007, p. 77), “a legitimação econômica permite ao sistema de dominação adaptar-se às novas exigências de racionalidade". Queiroz (1973) representava o técnico de vasto conhecimento sobre o assunto e poderia emitir juízo de valor. Portanto, era atribuída a ele a figura de alguém que sabe o que faz, garantidor da “inevitável redenção”, como conceitua Dupas (2007, p. 77).

O discurso favorável à construção da barragem pode ser verificado no texto do leitor Hailton Alves da Silva, no qual afirmava que o empreendimento resultaria em benefícios, mas os ribeirinhos tinham medo da obra, pois "choram, pranteiam, quando pensam em abandonar seus velhos berços que os viram nascer e irem para lugares outros por se determinar" (SILVA, 1973, p. 11). O autor ignorava os costumes e tradições locais diante do processo de deslocamento das comunidades. "Os habitantes insistiam em dizer que esta 'barragem desgraçada' vem nos matar, e não só a nós, como aos nossos bichinhos. Dou-lhe razões, pois não estão preparados para receber este benefício, e por que não esta dádiva" (SILVA,1973, p. $11)$.

Apreendemos que Silva estava ciente dos impactos sociais da obra e o deslocamento da população para outras regiões, como a de Bom Jesus da Lapa, onde foi implantado o Projeto Especial de Colonização Serra do Ramalho (PEC-Serra do Ramalho), ${ }^{10}$ em 1973, a 700 km

10 O PEC-Serra do Ramalho era organizado em 23 agrovilas, com lotes para moradias e parcelas rurais. Destinouse, inicialmente, a reassentar as famílias expropriadas de suas terras pela construção da barragem de Sobradinho. Contudo, acabou por ser oferecido a quem se interessasse e se submetesse a adaptar-se ao "enquadramento" do espaço e da situação, na época do regime militar. Quase todos os ribeirinhos que para lá foram forçados a ir 
distante da barragem, para assentar as famílias que viviam à margem do rio São Francisco. Ao ler o texto, fica evidente o menosprezo à cultura ribeirinha e à relação da população com seus espaços de referência social e sociabilidade. A afirmação do autor foi demonstrar um alinhamento com o discurso das forças do Estado para valorizar o processo de modernização com a captação de recursos financeiros e novos empreendimentos para a região.

Essa discussão se torna relevante como objeto de análise ao verificar o discurso dos colunistas Walter de Castro Dourado, Ermi Ferrari Magalhães e o articulista Dom José Rodrigues de Sousa, bispo da diocese de Juazeiro, pois problematizaram os aspectos sociais e os impactos da obra, demonstrando as tensões e contradições do discurso a respeito do progresso.

\section{O pensamento de Walter Dourado}

Desde as primeiras edições do periódico, Walter Dourado (1972) se colocou disponível para produzir reportagens na coluna "Histórias, Tradições, Comentários e Sugestões". No ano de 1973, ele publicou duas colunas com o texto "A bacia fluvial do São Francisco e a barragem de Sobradinho", no qual argumentou que o uso, a utilização, o tratamento e as transformações a serem feitas nas bases fluviais obedeciam a alguns acordos e convenções de âmbito internacional. O cronista afirmava que foram estabelecidas algumas normas para conciliar os diversos interesses no aproveitamento da queda d'água sem prejuízos para as atividades particulares ou da comunidade em geral (DOURADO, 1973, p. 8).

Essa determinação foi prevista em 1965, quando a comissão de Estudos dos Jurisconsultos para o Comitê Jurídico Latino-Americano elaborou projeto que aconselhava a realização de um exame para analisar a questão do aproveitamento dos sistemas fluviais, estabelecendo recomendações que envolviam obras de sentido agrícola e industrial. Dentre outras recomendações, Dourado (1973, p. 8) destacou que a utilização da água para a construção do lago não deveria "prejudicar a navegação, nem causar prejuízos substanciais".

Ao trazer essa discussão, Dourado (1973) tinha consciência da importância econômica da navegação local e dos interesses da elite política com a formulação de novos projetos para a

retornaram para os novos espaços desterritorializados, em torno do lago (GRUPO DE PESQUISA GEOGRAFAR, s. d). 
região, como a implantação dos projetos de irrigação que utilizariam a água do rio. Segundo Rabelo (2014), grupo de vozes concorrentes ao Projeto de Sobradinho foram veiculados no jornal juazeirense, entre eles os que defendiam a regularização da vazão do rio para favorecer a implantação dos projetos de irrigação, a partir da criação do lago artificial, e grupos preocupados com a manutenção da navegação e a situação da população atingida.

Nesses artigos, Dourado (1973) se mostrou porta-voz de grupos locais ao defender três aspectos: a) aproveitamento da força hidráulica; b) formação de um sistema de irrigação; c) continuidade da navegação, base econômica da região. Para o autor, deveriam ser preservados “os interesses empresariais, das empresas públicas ou privadas, no sentido do aproveitamento dos cursos d'água, cachoeiras (DOURADO, 1973, p. 8).

Na 48 edição, de 18 e 19 de agosto de 1973, o cronista retomou a discussão e defendeu que, para preservar princípios econômicos sadios, "deve-se considerar que a melhoria das condições de vida é perfeitamente compatível com os conceitos de liberdade política e doe direito de propriedade" (DOURADO, 1973, p. 8).

Para o colunista (1973), não haveria progresso se a construção da obra trouxesse impactos negativos aos setores vinculados à manutenção da navegação. Mas, como verificamos nas edições analisadas, a linha editorial do jornal considerava que a obra atendia à lógica do desenvolvimento regional. A função do Rivale como aparelho ideológico do Estado reforçava a política desenvolvimentista propagada pelo governo militar a partir da ideia de progresso que, para Dupas (2007, p. 73), se constitui “o mito renovado por um aparato ideológico interessado em convencer que a história tem destino certo e glorioso".

Analisando a conjuntura política da época, fica evidente que a retórica do Rivale se constituiu como uma estratégia enunciativa para defender o modelo econômico vigente. $\mathrm{Na}$ década de 1970, no contexto de política desenvolvimentista, opor-se a essa narrativa hegemônica não era uma decisão comum. A enunciação discursiva era "delicada, tendo em vista que, tratando-se de um projeto do regime militar, com uma ampla legitimidade social construída pelos discursos de engenheiros, de políticos e da imprensa, e com pouca possibilidade de crítica” (RABELO, 2014, p. 107).

Talvez Dourado tenha passado por essa situação. Na coluna, o cronista escreveu que o seu pensamento poderia ser um "devaneio", mas, com a intenção de ressaltar aos executores da 
obra "pontos nevrálgicos", questionou: "Não seria possível a formação do lago fora do leito do rio?', e "Por que não preferiu dessa forma menos prejudicial aos interesses dos ribeirinhos?" (DOURADO, 1973, p. 8).

Para o cronista, a solução seria a construção de barragens médias, pois não estariam sujeitas às perdas com a evaporação e a vazão do rio se manteria em condições adequadas no período de baixo volume pluviométrico. $\mathrm{O}$ autor avaliava que o rio poderia ser aproveitado de três formas - navegação, irrigação e energia - e seria o projeto considerado "mais humano" (DOURADO, 1973, p. 8).

Assim, o pensamento de Walter Dourado representava grupos locais que tinham interesse na construção da barragem de Sobradinho, preservando a navegação pelo rio São Francisco, cuja atividade econômica foi central para o desenvolvimento sociocultural da região nas primeiras décadas do século XX.

\section{Ermi Ferrari Magalhães e a navegação do rio São Francisco}

Assim como Walter de Castro Dourado, Ermi Ferrari Magalhães (1973) defendeu a continuidade da navegação pelo rio São Francisco. O debate iniciou-se quando a Câmara de Vereadores de Juazeiro realizou reunião extraordinária no dia 3 de julho de 1973 para deliberar sobre o projeto. Na pauta, a discussão do Porto de Juazeiro e documento assinado pelos prefeitos, associações comerciais das cidades de Juazeiro/BA e Petrolina/PE e a Companhia de Desenvolvimento do São Francisco (Codevasf), ${ }^{11}$ para preservar os interesses do município de Juazeiro em relação à cidade pernambucana de Petrolina.

Com a construção da barragem, as instalações do porto precisavam ser transferidas para um local acima da represa. Uma das opções previstas foi a instalação na fazenda Malhada da Areia, na margem direita do rio, portanto, no lado baiano. No entanto, representantes da Navegação Baiana do São Francisco que, até março de 1973, recomendavam o local supracitado, sugeriram a localização do porto provisório em outro ponto da margem direita ou, como alternativa, na margem esquerda, no povoado de Santana do Sobrado (PORTO/1, 1973, p. 2). A discussão

11 Em 06 de janeiro de 2000, a Codevasf teve sua área de atuação ampliada para a bacia do rio Parnaíba, incorporando à sua nomenclatura o vale do Parnaíba, sendo denominada, a partir de então, de Companhia do Desenvolvimento dos Vales do São Francisco e Parnaíba, mantendo a mesma sigla, Codevasf. 
central, contudo, era que os juazeirenses temiam perder poder econômico, com a possível fixação do porto na cidade de Petrolina.

No texto "Porto de Juazeiro", Magalhães (1973) retomou o debate e defendeu que a navegação continuasse livre até o porto de Juazeiro/Petrolina, com a implantação do Canal do Ingá ou Saco do Meio, compreendendo 400 metros de largura. O colunista (1973, p. 10) considerava que o estabelecimento de um porto provisório em outras localidades, como Malhada da Areia, Fazenda da Pedra ou Sobrado, geraria o "estrangulamento da navegação", trazendo impactos econômicos para "cinco mil pessoas diretamente ligadas à navegação, afetando também o comércio, a indústria e as rendas estaduais).

Mas a Companhia de Navegação do São Francisco apresentou um posicionamento distinto em relação à questão. Em carta publicada na edição 44, de 22 de julho de 1973, José Alonso Sartte e Esmeraldo de Oliveira Brito destacavam a instalação do canal do Ingá, como alternativa principal, contudo, não descartavam a hipótese de utilização de um porto provisório se os cálculos de engenharia conclú́ssem que a velocidade do canal não podia ser vencida pelas embarcações (SARTTE; BRITO, 1973, p. 7).

O conteúdo da carta é importante para compreender que um debate amplo sobre o porto foi instalado no seio da sociedade e gerou insatisfação, principalmente entre os juazeirenses, que não concordavam com a ideia de construir um porto provisório com receio de que Petrolina fosse beneficiada. Instaurou-se, a partir desse episódio, disputa entre os clãs políticos das duas cidades, tendo como alvo a questão do porto.

Na mesma edição, Magalhães (1973) informou que a Superintendência Nacional da Marinha Mercante não aprovou a instalação do canal do Ingá pelos altos custos à navegação. O cronista também alertou que, com a construção da barragem, a navegação seria interrompida e caberia somente à CHESF a decisão sobre o referido porto. Para Magalhães, a paisagem cultural também sofreria impactos. As barcas a motor que, desde o início do século XX, faziam o percurso de Juazeiro-BA a Pirapora-MG deixariam de singrar as águas do Velho Chico e não faria parte da "paisagem alegre" da região nem constituiriam "fonte de renda para o comércio e indústrias locais (MAGALHÃES, 1973, p. 14).

$\mathrm{Na}$ condição de ex-barqueiro, Magalhães identificou que a obra traria consequências para a vida dos barqueiros, seus colegas de trabalho e pertencentes ao seu vínculo social. 
Contudo, os esforços foram inúteis. Em 27 de abril de 1979, Magalhães escreveu que o ministro dos transportes, Elizeu Rezende, declarara que o Governo Figueiredo não tinha planos para manter a navegação. Em tom de tristeza, Magalhães (1979, p. 2) argumentou que cabia ao ribeirinho "viver miseravelmente, sem esperança e sem horizonte", pois "ao que parece, os homens do Governo, com poder de decisão, já compreenderam que nossa região herdou do São Francisco a humildade e conformação, pois até hoje sempre suportou tudo sem reclamar".

Na edição 331, divulgada em 22 de junho de 1979, Magalhães comunicou o fim da União dos Barqueiros, pois, com a consequente interrupção da navegação, os proprietários das barcas foram indenizados e restavam apenas 12 embarcações para o tráfego entre as cidades Juazeiro e Petrolina.Com o número reduzido de associados, a União não teve mais condições de sobreviver financeiramente. Todavia, apesar de lamentar, Magalhães buscou convencer o leitor - ou se convencer - de que a extinção do órgão representava um sacrifício em nome do progresso, representado pela construção da barragem de Sobradinho.

Em 1979, o Rivale publicou que a decisão sobre a interrupção da navegação suscitou reações de "saudosismo e sentimentalismo na população", mas, o que estava sendo preservado, segundo o discurso do periódico era a segurança dos passageiros e os custos à Companhia de Navegação (VAPORES, 1979, p.1). Sem reconhecer o problema do projeto Sobradinho à navegação, o jornal tentou tranquilizar a população, naturalizando a problemática da extinção dessa atividade e anunciando a criação futura de uma rota turística entre Juazeiro e Sobradinho, cujo projeto atual Vapor do Vinho é um empreendimento privado implantado nos anos 2000.

\section{Dom José Rodrigues de Sousa na contramão da retórica do "progresso"}

Voz ativa na defesa das populações atingidas pela construção da barragem de Sobradinho, o bispo da Diocese de Juazeiro, Dom José Rodrigues de Sousa, escreveu a coluna "Diocese em Foco", na qual denunciou as arbitrariedades da CHESF no que diz respeito ao deslocamento e indenizações às populações afetadas.

O pensamento de Dom José Rodrigues de Sousa em defesa da organização popular e reconhecimento dos direitos estava em consonância com o documento de Puebla, discutido na reunião da Confederação dos Bispos do Brasil (CNBB), realizada em Itaici-SP. Em sua coluna, destacava para o leitor que o documento defendia a "promoção e libertação integral" da 
população, abandonando "discurso amigo acerca do progresso e do desenvolvimento" (SOUSA, 1979, p. 2).

O posicionamento do bispo em defesa das populações atingidas se tornou explícito na edição 337, de 10 de agosto de 1979, quando o jornal publicou na íntegra a carta de Dom José Rodrigues em resposta às correspondências divulgadas pelo engenheiro João Paulo, da CHESF. O engenheiro alegava que membros da diocese dificultavam a titulação de terras em Remanso, especialmente no povoado de Marcos, e fazia críticas ao projeto de irrigação.

Em sua coluna, o bispo afirmou desaprovar o formato dos programas de irrigação e produção de energia elétrica conduzidos pela Codevasf e pela CHESF. Ele defendeu o direito à organização popular para garantir o direito à terra, em decorrência "das injustiças causadas ao povo, por causa da miséria maior da população, ao contrário do tão falado progresso, anunciado falsamente pelas propagandas oficiais" (SOUSA, 1979, p. 5).

O bispo defendeu que fosse convocada reunião com as famílias desalojadas ou com o Sindicato dos Trabalhadores Rurais das cidades atingidas para discutir o valor das indenizações: "Infelizmente, esse povo nunca foi ouvido e consultado! Esse povo é tido como 'ignorante, pobre, miserável, não sabe o que quer'. As decisões vêm sempre de cima para baixo, já prontinhas" (SOUSA, 1979, p. 6).

Pela análise da coluna e cartas, a diocese não foi contra a obra em si, mas contra a forma como ela estava sendo executada. Pelo embate nos meios de comunicação, Dom José Rodrigues foi o único a se posicionar a favor da população atingida pela barragem, indo na contramão da retórica do progresso defendido pelo periódico, pois buscou dar visibilidade à organização popular e às questões econômicas e sociais que atingiram a população local.

\section{Conclusão}

O discurso jornalístico do Rivale se alinhou com a defesa da construção da barragem de Sobradinho, tendo como base a retórica do progresso, promovendo o silenciamento ou a naturalização das questões sociais, ambientais e econômicas circunscritas à obra. A elaboração de cadernos especiais direcionados à defesa da barragem fez parte do aparato necessário para defender uma ideologia e colaborar com os projetos ditatoriais do regime militar. Ademais, consideramos que existiu uma tentativa de suprimir aspectos de uma determinada realidade para 
sustentar a estrutura de poder dominante, ofertando as bases de legitimidade social que o Estado defendia para o projeto Sobradinho.

Consideramos, contudo, que os cronistas tiveram posicionamentos divergentes à retórica hegemônica do jornal e demonstraram tensões e contradição ao projeto de implantação da obra. Walter de Castro Dourado $(1972 ; 1973)$ e Ermi Ferrari Margalhães $(1973 ; 1979)$ foram porta-vozes de interesses da elite local, pois trouxeram argumentos de que a obra causaria impactos econômicos e sociais na região com a interrupção da navegação. De maneira argumentativa, esses cronistas defenderam que a atividade fosse mantida, já que constituía, à época, uma das principais fontes de renda e comércio na região do Vale do São Francisco.

É importante atrelar aos dois colunistas o papel de figuras emblemáticas por demonstrarem, em seus discursos, questionamentos à interrupção da navegação, ao mesmo tempo em que indicaram uma tentativa de não querer comprometer-se com o projeto nacional propagado pelo Estado nem romper com representantes locais que apoiavam o projeto desenvolvimentista.

Dentre os colunistas, contudo, o bispo Dom José Rodrigues de Sousa foi o único a confrontar o posicionamento hegemônico, reproduzindo a posição da Diocese de Juazeiro, ao tornar público as arbitrariedades cometidas pela CHESF no que diz respeito às indenizações e relocação da população atingida. Portanto, houve uma mobilização para se fazer ouvir a voz das comunidades ribeirinhas.

Dom José Rodrigues denunciava os impactos negativos da obra, indo na contramão do posicionamento do jornal que buscou legitimar, não só o projeto Sobradinho, mas toda uma estrutura de poder que silenciava as vozes das famílias atingidas pela obra, considerada o símbolo do progresso da região.

Considerando o papel do jornalismo como forma de conhecimento, é possível refletir que a comunicação desempenhada pelo Estado e organizações jornalísticas como o Rivale, no processo de implantação da hidrelétrica de Sobradinho, se distanciou da sua função primordial em vários momentos. Como considera $\operatorname{MORAES~(1997,~p.~100),~os~meios~de~comunicação~não~}$ devem ser avaliados apenas como suportes ideológicos dos sistemas de dominação, mas também como lugares de produção de estratégias que buscam a reformulação do processo social. 
Por fim, concluímos que Sobradinho foi mais um projeto neoliberal que promoveu a acumulação de capital nas mãos dos empresários do agronegócio e das empresas multinacionais, em detrimento da sustentabilidade econômica e social dos núcleos urbanos e rurais ribeirinhos, cuja população depara-se hoje com novos problemas sociais, econômicos e ambientais, redimensionados em novas territorialidades. Mas essa temática pode ser objeto de novas investigações no futuro.

\section{Referências}

ANUÁRIO ESTATISTICO DO BRASIL-1973. Instituto Brasileiro de Geografia e Estatística (IBGE). Rio de Janeiro, v. 34, p. 964, 1973.

Disponível em: https://biblioteca.ibge.gov.br/visualizacao/periodicos/20/aeb_1973.pdf. Acesso em: 26 jun.2021.

ANUÁRIO ESTATISTICO DO BRASIL-2010. Instituto Brasileiro de Geografia e Estatística (IBGE). Rio de Janeiro, v. 70, p. 578. 2010. Disponível em: https://biblioteca.ibge.gov.br/visualizacao/periodicos/20/aeb_2010.pdf. Acesso em: 26 jun. 2021.

BARBOSA, Marialva. História cultural da imprensa: Brasil 1800-1900. Rio de Janeiro: Mauad X, 2010.

BARRAGEM de Sobradinho. Rivale, Juazeiro, ano 2, n. 30, p. 1, 15 abr. 1973.

BOURDIEU, Pierre. O poder simbólico. 6. ed. Rio de Janeiro: Bertrand Brasil, 2003.

BRANDÃO, Helena. Introdução à análise do discurso. Campinas, SP: Unicamp, 1994.

CHILCOTE, Ronald. Transição capitalista e a classe dominante no Nordeste. São Paulo: T.A Queiroz; Editora da Universidade de São Paulo, 1990.

COSTA, Ana Luíza. Barragem de Sobradinho: o desencontro cultural entre camponeses e técnicos do estado. In: VIANNA JÚNIOR, Aurélio (org.). Hidrelétrica, ecologia e progresso: contribuição para um debate. Rio de Janeiro: CEDI- Centro Ecumênico de Documentação e Informação.1990. p. 55-67. pm: https://documentacao.socioambiental.org/documentos/Q3D00028.pdf/. Acesso em: 12 dez.2020.

DOURADO, Walter. A recuperação do Vale do São Francisco. Rivale, Juazeiro, ano 1, n. 11, p. 6-7, 23 jul. 1972. 
DOURADO, Walter. A bacia fluvial do São Francisco e a barragem de Sobradinho. Rivale, Juazeiro, ano 2, n. 47, p. 8, 11-12 ago. 1973.

DOURADO, Walter. A bacia fluvial do São Francisco e a barragem de Sobradinho. Rivale, Juazeiro, ano 2, n. 48, p. 8, 18-19 ago. 1973.

DUPAS, Gilberto. O mito do progresso. Novos Estudos Cebrap, São Paulo, n. 77, p. 73-89, mar. 2007.

Disponível

em: https://www.scielo.br/j/nec/a/vSJfnDnZJfTkZGbLKdK45RN/?lang=pt. Acesso em: 22 jul. 2019.

ESTRELA, Ely Souza. Três felicidades e um desengano: a experiência dos beraderos de Sobradinho em Serra do Ramalho- BA. 2004. Tese (Doutorado em História) - Programa de Pós-Graduação em História, Pontifícia Universidade Católica, São Paulo, 2004. Disponível em: https://sapientia.pucsp.br/handle/handle/13049. Acesso em: 7 out. 2019.

GRUPO DE PESQUISA GEOGRAFAR. Projeto especial de colonização Serra do Ramalho. Universidade Federal da Bahia, s.d. Disponível em: https://geografar.ufba.br/projeto-especialde-colonizacao-serra-do-ramalho. Acesso em: 25 mar. 2020.

LOWENTHAL, David. Como conhecemos o passado. São Paulo, Projeto História, v. 17, p. 63-201, jul./dez.1998. Disponível em: https://revistas.pucsp.br/index.php/revph/article/view/11110. Acesso em: 26 mar. 2019.

MAGALHAES, Ermi Ferrari. Porto de Juazeiro. Rivale, Juazeiro, ano 2, n. 42, p. 10, 8 jul. 1973.

MAGALHAES, Ermi Ferrari. Porto de Juazeiro. Rivale, Juazeiro, ano 2, n. 44, p. 14, 21-22 jul. 1973.

MAGALHAES, Ermi Ferrari. Navegação do São Francisco fica sem vez. Rivale, Juazeiro, ano 8, n. 324, p. 2, 27 abr. 1979.

MAGALHAES, Ermi Ferrari. União dos Barqueiros. Rivale, Juazeiro, ano 8, n. 331, p. 2, 22 jun. 1979.

MORAES, Dênis de. Notas imaginário social e hegemonia cultural. Contracampo, Rio de Janeiro, n. 1, p. 93-102, jun. 1997. Disponível em: https://periodicos.uff.br/contracampo/article/view/17283/10921. Acesso em: 14 out.2019.

PARABÉNS, Juazeiro. Rivale, Juazeiro, ano 1, n. 10, p. 1, 15 jul. 1972.

PORTO/1. Rivale, Juazeiro, ano 2, n. 41, p. 2, 1-2 jul. 1973. 
QUEIROZ, Eunápio Peltier de. Carta ao deputado Jayro Sento-Sé. Rivale, Juazeiro, ano 2, n. 30, p. 1-3, 15 abr. 1973.

RABELO, Elson. Espectros do poder: uso político das imagens e discursos da imprensa - o Jornal Rivale, Juazeiro, Bahia. Interfaces Científicas, Aracaju, v. 3, n. 1, p. 105-117, out. 2014. Disponível em: https://periodicos.set.edu.br/index.php/humanas/article/view/1434/996. Acesso em: 20 ago. 2019.

REVEL, Jacques. Jogos de escala: a experiência da microanálise. Rio de Janeiro: Editora FGV, 1998.

RIBEIRO, Ana Paula Goulart. Imprensa e história no Rio de Janeiro dos anos 1950. Rio de Janeiro: E-papers, 2010.

SANTOS, Andréa. Travessias comunicacionais de um tipógrafo-jornalista: José Diamantino de Assis e as tessituras do moderno. Tese (Programa de Pós-Graduação em Comunicação e Cultura) - Universidade Federal do Rio de Janeiro, Rio de Janeiro, 2016. Disponível em: http://www.pos.eco.ufrj.br/site/teses_dissertacoes_interna.php?tease $=17$. Acesso em: 24 mar. 2020.

SARTTE, José Alonso; BRITO, Esmeraldo de Oliveira. Carta da Cia. de Navegação ao Jornal Rivale. Rivale, Juazeiro, ano 2, n. 44, p. 7-10, 21-22 jul.1973.

SENTO-SÉ, Jayro. Discurso proferido pelo deputado Jayro Sento-Sé em sessão realizada em 5 de abril de 1973. Rivale, Juazeiro, ano 2, n. 30, p. 3-10, 15 abr.1973.

SILVA, Ailton Alves da. Sobradinho em Pauta. Rivale, Juazeiro, ano II, n. 52, p. 11, 15-16 set. 1973.

SOBRADINHO. Intérpretes e Compositores: Luiz Carlos Pereira de Sá; Guttemberg Nery Guarabyra Filho. In: Pirão de peixe com pimenta. Rio de Janeiro: Som Livre, 1977. Disponível em: https://www.somlivre.com/mpb/sa-guarabyra-pir-o-de-peixe-com-pimentacd.html. Acesso em: 01 fev. 2019.

SOUSA, Jose Rodrigues. Carta resposta de Dom José Rodrigues ao eng João Paulo. Rivale, Juazeiro, ano 8, n. 337, p. 5-6, 10 ago. 1979.

VAPORES não voltarão ao nosso porto. Rivale, Juazeiro, ano 8, n. 352, p. 1, 30 nov. 1979.

Submetido em: 17.05.2020.

Aprovado em: 26.06.2021. 